\title{
Endotoxin levels in farming: absence of symptoms despite high exposure levels
}

\author{
ANNA RASK-ANDERSEN, ${ }^{1}$ P MALMBERG,${ }^{2}$ MONICA LUNDHOLM ${ }^{3}$ \\ From the Departments of Occupational Medicine and Clinical Physiology, ${ }^{1}$ University Hospital, Uppsala, \\ National Institute of Occupational Health, ${ }^{2}$ Stockholm, and Institute of Clinical Bacteriology, ${ }^{3}$ University \\ Hospital, Uppsala, Sweden
}

ABSTRACT The endotoxin concentration in air was measured in farms where 11 farmers hadB experienced febrile reactions or allergic alveolitis and in a random sample of farms with $17 \mathrm{~A}^{\circ}$ symptomless farmers. Samples were obtained during normal dairy farming in eight reference farmso (background samples) and in all farms during the handling of material which had probably caused symptoms or disease or, in reference farms, maximal spore exposure (worst case samples). In ${ }_{0}^{N}$ addition, parallel samplers were used in reference farms, one with a cyclone ( $5 \mu \mathrm{m}$ cutoff) and one without, to measure the dust and endotoxin concentrations in the respirable fraction and totak dust. The endotoxin worst case values varied from $<0.01$ to $>50 \mu \mathrm{g} / \mathrm{m}^{3}$ in symptom farms (median $6.4 \mu \mathrm{g} / \mathrm{m}^{3}$, geometric mean $2.2 \mu \mathrm{g} / \mathrm{m}^{3}$ ) and from $<0.01$ to $>50 \mu \mathrm{g} / \mathrm{m}^{3}$ in reference farms (median $42 \mu \mathrm{g} / \mathrm{m}^{3}$, geometric mean $29 \mu \mathrm{g} / \mathrm{m}^{3}$ ). This difference was not statistically significant. The backgroundo values in reference farms were 1.3 (median) and 0.4 (geometric mean) $\mu \mathrm{g} / \mathrm{m}^{3}$. The differences between samples with and without cyclone and between background and worst case samples were statisticallyo significant $(p<0.02)$. About $75 \%$ of the activity was found in the non-respirable fraction. Nos correlation was found between exposure to endotoxin and symptoms in farmers. There were weak, but statistically significant, correlations between endotoxin concentrations and total spore count oro dust concentrations. The surprisingly high endotoxin values in the respirable fraction of air from environments which apparently did not cause symptoms raises the concern that the Limulus amebocyte assay might be sensitive to other components in the dust rather than endotoxin.

Lipopolysaccharides from the outer part of the cell wall of Gram negative bacteria have potent biological effects and are called endotoxin. Endotoxin has been implied as a possible causative factor in byssinosis, ${ }^{\prime}$ in febrile reactions observed in workers in swine confinement buildings, ${ }^{2}$ and in grain elevator workers. ${ }^{3}$ Gram negative bacteria grow on moist organic materials which may become mouldy and exposure to dust from mouldy material may cause febrile reactions in dairy farmers. It is therefore conceivable that endotoxin may play a part in such reactions. Endotoxin is not believed to be antigenic but has adjuvant properties ${ }^{45}$ and might thus also be a cofactor in allergic alveolitis.

The aims of the present study were to measure endotoxin exposure during different farming activities, to study the respirability of dust fractions $s_{-}^{\circ}$ containing endotoxin, to correlate endotoxin exposure to symptoms, and to compare endotoxin exposure with other exposures associated with symptoms. Exposure to endotoxin and spores from moulds ando actinomycetes was measured in dairy farms of symptomless farmers and in farms where allergic alveolitiso or febrile reactions had occurred.

The results of the present study were surprising, since extremely high and variable endotoxin exposuren levels were observed in environments characterised byn no symptoms, as well as in environments associated with symptoms. These results imply that the recommended assay is possibly not suited for the analysis of air samples from the farming environment. Febrilees symptoms were observed in farmers exposed to high mould spore levels but low endotoxin concentration, indicating that these reactions may be caused by othere components than endotoxin in farm dust. 


\section{Material and methods}

\section{REFERENCE FARMERS}

Eighteen reference dairy farmers living in the vicinity of Stockholm were randomly selected from the national farm registry. All denied symptoms such as cough, recent febrile reactions to dust inhalation, wheezing in the chest, and dyspnoea. Exposure to endotoxin and spores of moulds and actinomycetes was measured at the end of the indoor feeding period in March and April 1987.

\section{ALLERGIC ALVEOLITIS AND FEBRILE REACTION GROUP}

The endotoxin and total spore concentrations of air was measured in 27 farms where the farmers had complained of febrile reactions to inhaled organic dust or had allergic alveolitis. In 11 of these farms samples were obtained which were considered to represent exposure believed to have caused disease (in five farms febrile reactions, in six farms allergic alveolitis). These farms were investigated as part of two other studies. One study was an epidemiological investigation of the incidence of febrile reactions to mould dust and allergic alveolitis ${ }^{6}$ and another study was a prospective investigation of exposures associated with these conditions.

\section{DUST SAMPLING}

Samples were obtained during one to two hours of normal dairy farming activities (feeding, cleaning, renewing of bedding material, background samples). In addition, a sample was obtained during the handling of mouldy materials associated with symptoms or believed to be associated with disease. A sample was obtained from reference farmers during the handling of material which was believed to cause the highest exposure to mould dust. These samples are referred to as worst case samples. An attempt was made to perform the sampling in a manner which reproduced the type of handling used by the farmer in normal farming or in the work tasks associated with symptoms. The worst case sampling usually lasted 5-15 minutes.

The samples were collected using personal samplers. The farmer or the investigator carried three filter casettes (Millipore, diameter $37 \mathrm{~mm}$ ) directed obliquely downwards on the chest. One filter holder on the right and left sides of the chest were equipped with polycarbonate filters with a pore size of $0.4 \mu \mathrm{m}$ (Nuclepore Corp, Pleasanton, California, USA). The airflow was $1 \mathrm{l} / \mathrm{min}$ and the filter casettes were used close phased. The total number of spores from moulds, actinomycetes, and bacterias were counted using epifluorescence microscopy (CAMNEA method, ${ }^{7}$ Department of Microbiology, University of
Agriculture, Uppsala, and at the National Institute of Occupational Health, Umeå). The third filter casette was equipped with a cellulose acetate filter $(0.8 \mu \mathrm{m}$, Millipore) and the casette was used open phased with an airflow of $10 \mathrm{l} / \mathrm{min}$ for analysis of endotoxin and total dust. These analyses were performed at the Institute of Clinical Bacteriology, University Hospital, Uppsala.

In reference farms worst case samples for the endotoxin concentration was measured using two parallel filter samplers, one of which was equipped with a cyclone (Cyclone, SKC, cutoff $5 \mu \mathrm{m}$ ) dimensioned to collect the respirable fraction of dust. The airflow was $1.9 \mathrm{l} / \mathrm{min}$ and the filterholders were hanging stationary at head level above the workplace. The farmers in reference farms performed the sampling and did not wear respirators during this time. In environments where febrile reactions or allergic alveolitis had occurred respirators were used during worst case sampling.

\section{LABORATORY METHODS}

Endotoxin was measured using the Limulus amebocyte lysate assay. ${ }^{89}$ The filters from the airborne dust samples were shaken in $10 \mathrm{ml}$ of pyrogen free water in a Stomacher washer. ${ }^{10}$ Serial dilutions and a negative and positive control were tested and the last dilution resulting in a stable clot was compared with commercial E Coli lipopolysaccharide (Sigma). The dilutions in three samples from the alveolitis group were not carried out beyond a dilution corresponding to about $50 \mu \mathrm{g} / \mathrm{m}^{3}$. In these cases a value of $100 \mu \mathrm{g} / \mathrm{m}^{3}$ was used corresponding to the next dilution step. For the purpose of illustrating the results, all values higher than 100 were truncated at $100 \mu \mathrm{g} / \mathrm{m}^{3}$ and a few samples below 0.01 were taken as $0.01 \mu \mathrm{g} / \mathrm{m}^{3}$.

Enumeration of micro-organisms was performed using epifluorescence microscopy ${ }^{7}$ within one to two days after sampling. The spores were extracted from the filters using $0.1 \% \mathrm{w} / \mathrm{v}$ peptone water with $0.01 \%$ Tween 80 . The spores in the aqueous extracts were fixed with formalin, stained with acridine orange, and filtered through a polycarbonate filter dyed black with Sudan black. The total number of spores (single spores and spores in aggregates) were counted using an eipfluorescence microscope, and the mean value of the two parallel samples was calculated.

\section{Statistics}

The statistical significance of differences between paired samples was evaluated using the Wilcoxon's signed rank test and the differences between unpaired samples were tested using the Mann-Whitney $U$ test. In addition, simple regression was used (Statview). 


\section{Results}

High and low endotoxin concentrations were observed in all environments studied. No symptoms were observed in reference farmers exposed to high concentrations of endotoxin. The median and geometric mean (based on truncated values) endotoxin concentration of reference farms was $42 \cdot 1(29) \mu \mathrm{g} / \mathrm{m}^{3}$ in the air, $7.0(7.4) \mu \mathrm{g} / \mathrm{m}^{3}$ in the respirable fraction, and $1.3(0.4) \mu \mathrm{g} / \mathrm{m}^{3}$ in background samples.

Seventeen paired measurements of the endotoxin concentration in the air and in the respirable fraction of air were obtained from reference farms. Background samples were also obtained in eight of these farms (fig 1). The use of a cyclone reduced the concentration of endotoxin by an average of two dilution steps (1/4). The difference was statistically significant $(p<0.02)$. The background samples (collected without cyclone) from reference farms were significantly lower than worst case samples, with or without cyclone $(p<0.02)$. There were no significant differences between the endotoxin concentration in reference farms and in the 11 farms where allergic alveolitis $(n=6)$ or febrile reactions to mould dust $(n=5)$ had occurred. The median endotoxin concentration in these farms was 6.4 and the geometric mean value was $2 \cdot 2 \mu \mathrm{g} / \mathrm{m}^{3}$.

There was a poor, statistically significant correlation between endotoxin concentration and total spore count in 56 samples $\left(p<0.02, R^{2}=0.08,44\right.$ worst case samples and 13 background samples, fig 2). The endotoxin concentration also correlated with the total

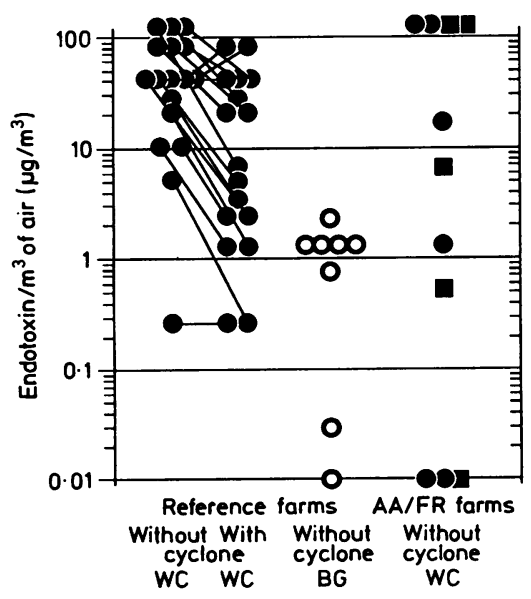

Fig 1 Endotoxin concentration in reference farms and in representative samples from farms where one or more farmers has had attacks of febrile reactions (FR, squares) or allergic alveolitis (AA, circles). Filled symbols represent worst case samples (WC), open circles represent background (BG) samples. Paired samples are joined.



Fig 2 Relation between total spore count and endotoxin concentration. Filled symbols: worst case samples from 44 farms. Open symbols: background samples from 13 farms.

dust concentration measured in 14 farms of symptomatic farmers. The correlation, however, was weak $\left(p<0.05, R^{2}=0.05, n=22\right)$. The total dust concentration in these worse case samples varied between 0.05 and $19 \mathrm{mg} / \mathrm{m}^{3}$, with a geometric mean value of $0.58 \mathrm{mg} / \mathrm{m}^{3}$. Background samples had a geometric $\stackrel{D}{\Omega}$ mean value of 0.44 and a range of $0.1-3.6 \mathrm{mg} / \mathrm{m}^{3}$.

The total spore concentration in the samples from 3 the 11 farms where febrile reactions or allergic? alveolitis had occurred was $5.6 \pm 5.9 \times 10^{9}$ spores $/ \mathrm{m}^{3}$ $($ mean $\pm \mathrm{SD})\left(\right.$ range $\left.0.59-17 \times 10^{9}\right)$. The total spore count from all reference farm samples was $0 \cdot 12 \pm \frac{\Phi}{3}$ $0.20 \times 10^{9}$ spores $/ \mathrm{m}^{3}$ (range $\left.0.0001-0.65 \times 10^{9}\right)$. The difference in spore concentrations between symptom 3 . farms and reference farms was statistically significant $(p<0.001)$.

\section{Discussion}

Endotoxin has a wide range of biological effects afte parenteral administration. It is, for example, a welp known pyrogen. The effects of inhaled endotoxin arev less well studied; but it can cause febrile reactions and airways obstruction. Thus it has been suggested that inhalation of endotoxin may play a pathogenetic parf in byssinosis and in febrile reactions to grain dust an swine confinement building dust. ${ }^{1-3}$ It is, howeveres difficult to ascertain a causal relation since the dusts causing these conditions are complex mixtures of organic particles. Maximal endotoxin concentrations in dust associated with byssinosis are often in the range 
$0 \cdot 1-10 \mu \mathrm{g} / \mathrm{m}^{3}$ of air. ${ }^{112}$ These concentrations are not enough to cause symptoms when purified lipopolysaccaride is administered as a nebulised solution.$^{1314} \mathrm{It}$ has been suggested that the particulate form of endotoxin containing dust may contribute to the toxicity of endotoxin.

Gram negative bacteria grow on and adhere to organic material. This may explain the observation that most of the activity was associated with the nonrespirable fraction of farm dust. This finding is in accordance with the observations of Olenchock et $\mathrm{al}^{15}$ who found a variation in airborne endotoxin concentrations ranging from $2 \mathrm{ng} / \mathrm{m}^{3}$ for the smallest particle size up to $400 \mathrm{ng} / \mathrm{m}^{3}$ for the largest sized particles. Because approximately $75 \%$ of the endotoxin activity resided in the non-respirable fraction of inhaled dust this may contribute to the absence of reactions in farmers to inhaled dust. Nevertheless, almost half the samples of respirable dust had endotoxin concentrations exceeding $10 \mu \mathrm{g} / \mathrm{m}^{3}$.

The finding in the present study that high endotoxin concentration ( $50 \mu \mathrm{g} / \mathrm{m}^{3}$ of air or more) in the respirable fraction of dust did not appear to cause symptoms may be interpreted in three ways. Thus previous conclusions concerning a role of inhaled endotoxin may need further study. The results of the present study may have been influenced by methodological factors causing higher entodotoxin activity than in previous studies. Finally, farm dust may contain factors that influence the endotoxin assay but does not have biological effects. We suggest that the third possibility in particular is further studied before more far reaching conclusions are drawn. Whereas symptoms in farmers were well correlated with exposure to spores from moulds and actinomycetes, both low and high endotoxin concentrations were found in dust associated with symptoms. This indicates that other factors than endotoxin could cause the febrile reactions in farmers exposed to mould dust.

Gram negative bacteria are vulnerable to dessication but endotoxin effects are retained even when the bacteria are dead and fragmented. The extraction of endotoxin from the samples using a stomacher washer $^{10}$ may have been more efficient than methods used in previous studies. Thus the endotoxin concentration may theoretically have been underestimated in other studies where a relation between exposure to endotoxin and symptoms has been suggested based on much lower concentrations of endotoxin than has been found in this study.

There is little reason to believe that contamination of the samples or equipment, or both, was the cause of the high values. There was a logical relation between total and respirable dust endotoxin concentrations in worst case and background samples. Errors due to contamination should be random rather than cause systematic effects as observed in the present study. The determinations were made in three batches separated by long time intervals and all three runs showed a similar pattern.

The endotoxin concentration is measured using a biological test (the Limulus amoebocyte lysate assay) which is believed to be highly specific. ${ }^{16}$ Some investigators have challenged this belief and suggested that perhaps other materials may also influence the result of the test. ${ }^{17}{ }^{18}$ Thus the Limulus amoebocyte assay may possibly be sensitive to some component of the dust other than endotoxin.

Peptidoglycan from the cell wall of Gram positive bacteria may induce the reaction but the activity of peptidoglycans is 1000 to 400000 times less than lipopolysaccharides. ${ }^{16}$ Mannans and dextrans may also activate the limulus assay. ${ }^{19}$ Specific mannans are found in the cell wall of yeast cells of the Candida species and may perhaps also be found in other components of farm dust. There was poor correlation between endotoxin concentrations and the spore concentration indicating that other constituents of the dust might be implicated as a putative false source of endotoxin activity rather than spores of moulds and actinomycetes.

In view of the uncertainties regarding the validity of these results we think that the findings of the present study indicate a need for further analysis of the endotoxin test when applied in new environments with complex dust mixtures.

We gratefully acknowledge the help of Dr Urban Palmgren and laboratory technician Maria Eriksson for the sampling and enumeration of spores. We also thank Mrs Mary Reuterdahl for preparing the manuscript. The study was supported by the National Work Environment Fund grant AMF 86-1353.

\section{References}

1 Rylander R. Bacterial toxins and etiology of byssinosis. Chest (suppl) 1981;79:34-8.

2 Clark S, Rylander R, Larsson L. Airborne bacteria, endotoxin and fungi in dust in poultry and swine confinement buildings. Am Ind Hyg Assoc J 1983;44:537-41

3 doPico GA, Reddan W, Flaherty D, Reed C, Tsiatis A. Health effects of occupational grain dust exposure. Am J Ind Med 1986;10:298-9.

4 Dinarello CA. Molecular mechanisms in endotoxin fever. Agents Actions 1983;13:470-86.

5 Kutz SA, Mentnech SM, Olenchock SA, Major PC. Immune mechanisms in byssinosis. Chest (suppl) 1981;79:56-8.

6 Malmberg P, Rask-Andersen A, Höglund S, Kolmodin-Hedman B, Read-Guernsey J. The incidence of organic dust toxic syndrome and allergic alveolitis in Swedish farmers. Int Arch Allergy Appl Immunol 1988;87:47-54.

7 Palmgren U, Ström G, Blomquist G, Malmberg P. Collection of 
airborne micro-organisms on Nuclepore filters, estimation and analysis-CAMNEA method. J Appl Bacteriol 1986;61:401-6.

8 Levin J, Bang FB. The role of endotoxin in the extracellular coagulation of Limulus blood. Bulletin of Johns Hopkins Hospital 1964;115:265-71.

9 Rylander R, Morey P. Airborne endotoxin in industries processing vegetable fibers. Am Ind Hyg Assoc J 1982;43:811-2.

10 Sharpe AN, Jackson AK, Stomaching A. A new concept in bacteriological sample preparation. Appl Microbiol 1972; 24:175-8.

11 Haglind $P$, Rylander R. Exposure to cotton dust in an experimental cardroom. Br J Ind Med 1984;41:340-5.

12 Haglind P. The byssinosis syndrome. Epidemiological and experimental studies. Gothenburg: University of Gothenberg, 1984. (Thesis.)

13 Cavagna G, Foà V, Vigliani EC. Effects in man and rabbits of inhalation of cotton dust or extracts and purified endotoxins. $B r$ J Ind Med 1969;26:314-21.

14 Haglind P, Bake B, Rylander R. Effects of endotoxin inhalation challenges in humans. In: Wakelyn PJ, Jacobs RR, eds. Proceedings of the eighth Cotton Dust Research Conference. $\mathrm{D}$ Atlanta, Georgia, 1984. Memphis: National Cotton Council, 은 1984:105-6.

15 Olenchock SA, May JJ, Pratt DS, Morey PR. Endotoxins in the $\overrightarrow{\overline{\vec{S}}}$ agricultural environment. Am J Ind Med 1986;10:323-4.

16 Wildfeuer A, Heymer B, Schleifer KH, Haferkamp O. Investigations on the specificity of the Limulus test for the detection of endotoxin. Appl Microbiol 1974;28:867-71.

17 Maitra SK, Nachum R, Pearson FC. Establishment of beta- $\overparen{D}$ hydroxy fatty acids as chemical marker molecules for bacterial endotoxin by gas chromatography-mass spectrometry. Applos Environ Microbiol 1986;52:510-4.

18 Pearson FC, Bohon J, Lee W, et al. Characterization of Limulus amebocyte lysate-reactive material from hollow fiber dialyzers. Appl Environ Microbiol 1984;48:1189-96.

19 Mikami T, Nagase T, Matsumoto T, Suzuki S, Suzuki M. Gelation of Limulus amebocyte lysate by simple polysaccarides. Microbiol Immunol 1982;26:403-9. 